\title{
DISTANCE EDUCATION FOR TEACHER TRAINING PROGRAM IN RURAL AREAS: A NECESSARY STRATEGY FOR COVID-19 SITUATION
}

\author{
Md. Solaiman Jony ${ }^{i}$ \\ Assistant Professor, \\ Institute of Education and Research, \\ Khulna University, \\ Bangladesh \\ orcid.org/0000-0003-0433-0878
}

\begin{abstract}
:
Like other countries around the world, distance education approach has been exceptionally beneficial for the continuation of teaching learning activities in Bangladesh during the covid-19 pandemic situation. Teacher training is a very crucial and integrated part of teaching learning activities as it helps to enhance the quality of teaching. Despite the continuation of teaching learning through online and distance education approach, the teacher training was not happening on a regular basis during this pandemic period. Therefore, this study is an attempt to explain the necessity of distance education for the persistence of teachers training program during and after the covid-19 pandemic situation in order to maintain a continuity in the professional development especially for teachers in the rural areas in Bangladesh. This study was conducted by following the concurrent mixed method research design. Data were collected with the help of a semistructured questionnaire and interview schedule from the secondary school teachers from rural areas, trainers and experts in distance education and teacher training program. The results of this study indicated that distance education can play a significant alternative role in arranging teacher training program for teacher across the country during this covid-19 crisis moment. Moreover, the participants also agreed that the continuation of distance education approach should be paralleled with the conventional approach for teacher training program in the post covid-19 period as it brings more flexibility, accessibility, inclusiveness and responsiveness. However, the study also revealed few challenges which can impair the arrangement of distance education in teacher training programs.
\end{abstract}

Keywords: distance education, teacher training, rural teachers, Covid-19 pandemic

${ }^{\text {i } C o r r e s p o n d e n c e: ~ e m a i l ~ j o n y s o l a i m a n @ g m a i l . c o m ~}$ 


\section{Introduction}

In Bangladesh, the role and importance of a teacher in students' learning is highly significant; mainly at the primary and secondary level. Specially, students from rural areas are heavily depended on the teachers for continuation of learning. Whatever the teacher teaches, is the main learning support to the students apart from text books. Therefore, if teachers are well educated, well trained and skilled with modern teaching methods and techniques, and can properly utilize knowledge and skills in teaching, students are the first ones who are receiving direct and greater benefit (National Education Policy, 2010).

However, regrettably, in Bangladesh most of the teachers from rural areas are not highly educated and well trained, not very much familiar with the modern teaching methods, and on top of these, teaching is not their first preference of job. As a result, most of the teachers suffer from lack of passion for the job and they hardly try to improve their teaching quality. In addition, the opportunity of in job training and higher education are very limited in numbers. In rural areas of Bangladesh, there are very few teachers who can teach the subject content properly to the students as one teacher tend to teach all the subjects and due to limited number of subject specialist teachers. Most of the teachers do not distinguish the proper teaching method and technique and mostly depend on the lecture method; where students listen to teacher and later on memorize (National Education Policy, 2010).

A teacher is the person who sketches the soft line of a beautiful picture in the mind of students' while teaching. A good teacher has strong content knowledge, pedagogical knowledge and a structured and planned approach to teaching. At the same time, a teacher needs to understand how students learn. It is equally important that a teacher knows how to teach according to situation of the students and classroom environment (Burns, 2011).

The term 'good teacher' means high quality teacher who is the most important factor in a child's education. Good quality teaching has a strong correlation to students' achievement. Rockoff (2004), in a 10-year study of the same set of teachers, estimated that differences in teacher quality account for 23 percent of the variation in student test scores. Hanushek (1992) [cited in Burns, 2011], estimates that the difference between having a good teacher and a bad teacher can exceed one grade level in annual achievement growth. Felch et al. (2010) [cited in Burns, 2011], concluded that the difference between success and failure was not a function of income or family or native intelligence, but rather the result of the quality of the child's teacher. Hanushek et al. (1995, 1997) [cited in Burns, 2011], found that teachers' education (55\%) and level of experience (35\%) impact most on student achievement in non-industrialized countries.

Professional development programs for teachers should be focused on helping teachers to develop their content and pedagogical knowledge, skills, attitudes, and attempts to improve teaching. It should also help to teacher to assess the work environment and to realize how information related to students learning is important for 
adjusting or improving teaching. Darling-Hammond (2008) [cited in Burns, 2011], suggests that on average teachers need at least 49 hours per academic year before they show any sign of improvement. According to Burns (2011), "high-quality teaching demands high-quality professional development. And high-quality professional development demands time and resources. Countries like Sweden and the Netherlands require teachers to have 104 and 169 hours of professional learning per year respectively beyond the hours they spend on instructional planning; Singaporean government pays its teachers for 100 hours of professional development each year; South Korean teachers are required to take 90 hours of professional development courses every three years, most of which they do online".

Distance education is one of the modern methods of learning and depends mainly on the teacher who gives lectures from the virtual classroom, and the student can receive the lecture anywhere in the world, and the virtual classroom opens to everyone for interactive discussion and participation in a way that achieves benefit for all students from anywhere in the world (Al-Nuaimy et al., 2021). Distance education has emerged as an effective mode in the area of teacher education throughout the world (Shah, n.d.). According to Gultekin (2006), distance education provides important contribution to education systems. Teacher training is one of the fields in which distance education is used widely. Distance education is used for teacher's graduate education, teacher's preservice and in service training at elementary and secondary education level.

Distance education is used to improve the professional development of teachers, extend existing knowledge and skills, and help them to acquire new ones. Some countries use distance education to provide support for both new entrants to teaching and experienced unqualified teachers. Distance education is also used to raise skills, deepen understanding and broaden knowledge of teachers (Sifuna, 2011).

According to Tahir Tavukcu et al. (2011), implementation of distance education method is applied in two ways as synchronous and asynchronous. Synchronous communication is a face-to-face communication that occurs at the same time but people do not have to be at the same place during that period. In the field of distance education, this communication type is based on sharing data and information by implementing two or more computers' connections with each other over a computer network. In asynchronous applications, course content is presented to students as one way, and interaction is extremely limited. TV broadcast systems or materials such as books, CD ROMs, and video tapes are used in this application (Jonassen, 2000).

Moon et al. (2005) [cited in Burns, 2011], suggest that distance education model irrespective to different model, must be grounded by a specific set of learning objectives: increasing teachers' knowledge in a particular domain, helping teachers to master content-specific pedagogical approaches, or developing other practical skills such as questioning techniques.

Distance education has become a concerning issue to most universities, educational institution, educators, trainers and students now a days during the ongoing pandemic situation all over the world. Although there are many universities, educational institutions and centers in the developed countries who provide distance education 
program throughout the academic year, it's relatively a new approach for educators, trainers, teachers, students and educational institutions in Bangladesh (Gopal et al., 2021). The COVID-19 pandemic has played a vital role in bringing out and practicing the distance education approach in our educational institutions.

The outspread of COVID-19 has not only affected human health but also the education system. Educational institutions across the world suspended their regular academic activities in order to stop the further spreading the diseases and moved to online education system. During the pandemic situation the educational institutions has been shut down for health and safety issue for quite a long time in Bangladesh. As a result, both teachers and students are out of touch from regular schooling system. However, many alternatives have been introduced for the students in the form of online and distance education to keep them engaged into the learning. The introduction of remote learning through online education as an alternative has been a new concept for many educators in Bangladesh as well as for the teachers, specially who are in primary and secondary level. Hence, it remains as a challenge for the teachers to adapt themselves with so many new changes during this pandemic.

On top of these, teachers training program which works as a light house for many of the existing teacher has not been on its regular pace during the pandemic time. Instructions and guideline have been supplied to the teachers to confront this challenging situation rather than hands on training which was mostly necessary. Thus, the introducing an alternative to the present face-to-face training system is utmost priority for the teachers. The post pandemic situation also demands all of us to contemplate such alternative due to many new restrictions already imposed by the authority across the country and world.

Nevertheless, it is an optimistic indication that the government of Bangladesh has offered its extended supports to use the Information and Communication Technology (ICT) to digitized the education sector, focusing on teaching learning quality. Even schools located in rural areas also have the opportunity to use ICT. The World Bank is working closely with multiple government agencies and departments in Bangladesh to support the primary and secondary education sector during the covid-19 emergency situation. According to the World Bank (2021) report, the online or remote learning initiative is expected to continue through a hybrid model in future in Bangladesh. The government recently approved national five-year plan (July 2020- June 2025) has reaffirmed the government's commitment and support. The upcoming national education policy is also expected to incorporate many of these activities as priority areas of focus. Therefore, if it is possible to train the teachers by distance education program during and after the pandemic situation with the help of ICT, it can be a very good channel for improving the quality of the teachers. Moreover, the professional development for teachers will not be hampered even by the shutdown of educational institutions. 


\subsection{Objectives of the study}

The main purpose of the study was to rationalize the importance of the teacher training program through distance education during and after the pandemic situation for rural teachers in Bangladesh for the development of teaching learning quality. Therefore, the study was comprised of following objectives:

1) to familiarize the concept of distance education in teacher training program among teachers in rural areas of Bangladesh;

2) to elucidate the necessity of distance education in teacher training program during and post covid-19 pandemic situation to improve the quality of teaching.

\section{Methodology of the study}

The methodology of the study is described through: (a) study nature and research design, (b) respondents and the sampling design (c) instruments of data collection and (d) data analysis. These are spelled out in the following sections.

\subsection{Nature of the study}

This was a mixed method research in nature highlighting both quantitative and qualitative approach of research. According to Creswell (2012), mixed methods is a research approach, popular in the social, behavioral, and health sciences, in which researchers collect, analyze, and integrate both quantitative and qualitative data in a single study or in a sustained long-term program of inquiry to address their research questions. In this study, quantitative survey followed by in-depth qualitative questionnaire and interviews took place with targeted samples. This study was based on a concurrent mixed method design where both quantitative and qualitative data was collected and results were interpreted simultaneously.

\subsection{Sampling design}

The respondents of the study were the teachers of secondary schools from rural areas. Experts in distance education program, and teacher trainers were also included as the respondents. In order to select the sample of teachers' proportional stratified random sampling technique was followed. List of secondary school teachers from rural areas were collected from the list of trainees who participated in the government teachers training colleges. Total 98 teachers were selected for this study. 3 university professors who has expertise in distance education and teacher training program, and 5 trainers from government teachers training colleges were chosen on the basis of convenience sampling to collect required information for the study.

\subsection{Instruments of data collections}

A semi structured questionnaire (with open ended and closed ended questions) for the teachers was developed and administered to gather data regarding perception of distance education, importance of teacher training program for improving teaching quality, scope 
of continuous professional development through teacher training program, practicality of the training program during and after the pandemic situation and opportunity to avail and so on.

An unstructured interview schedule with open ended questions for the experts of distance education program and teacher trainers were used to know their perception regarding the importance of introducing distance education program into the teacher training program during and after the pandemic situation as an alternative of present structure for the continuation of teachers' professional development and improvement of teaching learning quality.

\subsection{Data analysis}

Data from closed ended questionnaire, and closed ended interview was presented in quantitative form. The quantitative data from questionnaire were analyzed in terms of factors (Frequency, Percentage etc.). For the qualitative data, different themes were identified from the interview and questionnaire, and data were analyzed thematically.

\section{Findings of the study}

Distance education is an approach in which students or participants are not required to be physically present in a classroom setting. Technology plays a vital role in the actualization of distance education. In a distance education program, there must be teacher or instructor, students or participants, and course or curriculum. Distance education is unlike the regular education in terms of physical presence of a student or teacher, however, it requires higher degrees of discipline and planning to successfully complete the course of study or program.

\subsection{Teachers' responses}

A total number of 98 school teachers, 62 male and 36 female, who teach in the schools of rural areas in Bangladesh were answering the questionnaire. For closed ended questions teachers were given the opportunity to choose more than one options. Therefore, the cumulative percentage may show over $100 \%$ for few responses. The following section describes their responses regarding distance education, teacher training program and other related queries.

\subsubsection{Teachers' understanding about the goal of teacher training program}

All of the teachers $(100 \%)$ agreed that the main goal of teacher training program should be for their professional development. However, the responses also found the most pertinent goals of teacher training program, which are: enhance teachers' content knowledge and pedagogical skills (92.85\%), enable the teacher to understand students' psychology and individual difference $(77.55 \%)$, developed a positive attitude towards teaching and increase self-confidence (62.24\%), enable the teacher to identify learners 
need and help the students to learn $(80.61 \%)$, and enable the teacher to properly use instructional facilities in teaching learning activities $(69.38 \%)$.

\subsubsection{Teachers' perception about the relation between teacher training program and teaching quality improvement}

All the teachers $(100 \%)$ think, there is a positive relationship between the teacher training program and teaching quality. The opportunity to take part in teacher training program would certainly help them to improve their teaching quality. According to the teachers, teacher training positively helps to handle the classroom environment and manage the classroom effectively, helps to manage teaching learning activities and assessment of students, helps to create student friendly learning environment which involve the students in learning and enhance their learning achievement.

\subsubsection{Teachers' concept about distance education program}

Most of the teachers are familiar with the term 'distance education'. According to the teachers' who are familiar (88.77\%) with the term, defined 'distance education' as: teaching through the use of internet and technology $(90.80 \%)$, special teaching method with structured planning (58.62\%), method of communication by electronic technology $(41.37 \%)$, and teachers and students can attend class from different places $(82.75 \%)$.

\subsubsection{Teachers' perception about distance education in teacher training program}

According to the teachers, distance education in teacher training program will enable them to join the training program without moving from their workplace. Teachers also answered that distance education in teacher training is a new model to teacher education which allows them to support career development. Moreover, distance education can include a large number of teachers in training programs at same time.

\subsubsection{Teachers' perception about the advantages of distance education in teacher training program}

According to the response of teachers, distance education has the advantages like; it provides different and alternative education options $(82.65 \%)$, provides flexibility and easy access $(73.46 \%)$, can be useful to facilitate mass education in short time $(41.83 \%)$, provides individual and independent learning (39.79\%), provides a relaxed learning environment for students or participants (85.71\%), reduces the cost of education (14.28\%), provides a standard in training program $(21.42 \%)$, minimizes the disparity of participation $(56.12 \%)$.

\subsubsection{Teachers' perception about the disadvantages of distance education in teacher training program}

The disadvantages of distance learning according to the response of teachers are: lack of communication and interaction (34.69\%), heavily depends on access facilities and communication technologies like internet, mobile, laptop, etc. (78.57\%), not effective in 
developing the affectional and psychomotor behaviors (40.81\%), not useful for participants not having independent study habit (46.93\%), cost can be high for the use of modern technology $(67.34 \%)$, not useful for teachers not having proper knowledge on technology $(60.20 \%)$.

\subsubsection{Teachers' perception about the role of distance education during the covid-19 situation}

Teachers had the opportunity to answer this question without any given restriction. Hence, themes were identified from their given responses. According to the respondent teachers, distance education can be a useful method for teacher training as an alternative method of traditional face-to-face training approach. During the covid-19 pandemic situation teachers are given new teaching learning instructions including the use of online classes for students every now and then. Thus, teachers need proper training to adapt themselves with the new changes. Moreover, teachers who are not skilled in using ICT also need proper orientation during the pandemic situation in order to follow the instruction of online education. Therefore, distance training program can play a vital role in developing teachers' pedagogical skills. Teachers also agreed that as their workplace is in remote areas, so with the help of distance education they can easily take part in the arranged training programs during this pandemic situation without travelling and any health risk. Teachers termed distance education program as a flexible one as one can learn from home, from workplace, or anywhere with the help of a mobile or laptop and internet connection.

\subsubsection{Teachers' perception about the importance of distance education in post covid situation}

According to the responses from the teacher, the pandemic situation has forced a massive transition from traditional face-to-face teaching learning to internet and technology based online distance education. The post covid-19 education system may not experience the previous traditional approach operating to its full function within a short period. Hence comes the importance of online and distance education program in all level of education. Teacher training program is an integral part of teachers' professional development. In order to maintain the consistency of teachers' development and improve teaching quality, teachers need to be under regular teacher training program though out the academic year. However, teachers who are working in the rural areas, not always receive the opportunity to participate in these training programs regularly due to a number of reasons, like: shortage of teachers in the workplace, workload, traveling requires time and money, limited number of training sessions arranged and so on. On top of these, the impact of covid-19 pandemic will restrict the pace of previous normal activities which will also reflect in the teacher training programs. Nevertheless, the teachers have no alternatives except adapting with the upcoming changes. As per the response of teachers, if the implementation of distance education is ensured in the post covid situation, it can minimize lot of these challenges. 


\subsection{Experts' responses}

Total 8 experts, 3 university professors and 5 teacher trainers from teacher training colleges, were interviewed to get their opinion regarding distance education, the importance of distance education in teacher training program and how distance education can be implemented effectively as an alternative in the present changing situation and so on.

\subsubsection{Importance of distance education}

Experts agreed that distance education is very much useful in this pandemic situation and is playing a vital role in the advancement of teaching learning activities although the educational institutions are forced to shut down to stop the outbreaking of covid-19 disease. Teachers and students can take part in teaching learning activities without physical presence unlike the traditional schooling system and they have the opportunity to decide when and where to study which means more flexibility. Distance education creates opportunity for remote learners which means accessibility is increased. Through distance education students and participants have the opportunity to get access to experts in particular courses even if they are not in same city or country. However, on the flip side, distance learning demands discipline and self-motivation from the students, and organized planning from teacher. Without ensuring these, distance education may not be successful to serve its purpose.

\subsubsection{Importance of distance education in teacher training program}

According to the experts, teacher training program should be a continuous effort which will increase the pedagogical and subject knowledge, develop communication skills and self-awareness, develop the curiosity and eagerness to learn, help to understand student psychology and learning needs, and develop resilience. The ultimate goal of teacher training is achieved when the overall teaching learning quality is improved. To ensure an effective professional development, teachers at all level need to be a part of training program constantly. The idea of distance education is to connect teacher and students irrespective to time and place. Therefore, distance education can be one of the most convenient options to engage the teachers in teacher training program discontinuously, especially for those who are in remote places.

\subsubsection{Advantages of distance education in teacher training program for rural teachers}

The experts explained multifaceted benefits of distance education if used in teacher training program for rural teachers. Most importantly, participants do not have to commute anywhere to attend classes as they can join from anywhere which can save money and time spent in travelling to training institution. Distance education can be useful to promote self-learning and develop self-confidence among teachers as it uses communication media, like face-to-face sessions through internet, lectures on TV and radio, audio recording, email, teleconference and printed modules for independent study. In rural schools there is a general tendency that few teachers avail the opportunity 
to receive all the training program. According to the experts, the concept of distance education is to bring more flexibility and create more accessibility to the participants. Therefore, in teacher training program the idea of distance education can include more rural teachers especially female teachers who find it difficult to move from work station. Moreover, due to the limitations of the resources like training person, training venues, accommodation for participants, and expenditures, teachers who are in need of training badly sometimes do not get opportunity immediately. The experts' urged, distance education might be experimented to see the results of these issues.

\subsubsection{Advantages of distance education in teacher training program during covid-19 pandemic situation}

The experts have opined, the covid-19 pandemic is a global crisis that forced us to stop and limit our regular education activities including professional development program for teachers. However, during this crucial time teachers need the support of these training program most as new and challenging initiatives like online classes and assignments are introduced as alternatives of regular classroom activities and examination. Therefore, teachers need proper training and guidance on how to implement these initiatives to the teaching learning activities. Thus, distance education programs for teacher training can be solution. Moreover, during this pandemic where everyone is asked to take proper health care by staying at home and restrict movement, distance education is the only possible way to work for the teacher training programs. Experts unanimously agreed that with the help of distance education, the continuous development program for teachers can be safeguarded even in the pandemic time.

\subsubsection{Implementing distance education approach in teacher training program as an alternative to present face-to-face training approach}

Experts suggested, the successful use of distance education is related with the availability of communication technology like internet, web-based platform, mobile, computer, laptop, TV, radio, flexibility and relevance with academic teaching learning. Despite having a lot of advantages, according to the experts, distance education has some limitations too which need to be considered while implementing. Among many of the limitations few are; difficult to stay focused, motivated and connected with the instructor or teacher, unavailability of electricity, internet connection and device for connection, too much dependency on technology, immediate feedback from instructor and so on. Distance education also restricts social interaction among the peers which may be a concern. Therefore, in order to make proper implementation of distance education, not only during but also after the covid- 19 pandemic time, these above-mentioned issues need to be taken care of by the proper authority. Off-line learning options and multiple options for communication should be provided. Communication technology and devices should be made available at low cost and participants should be given opportunity and encouragement to participate into the training programs as per their professional need. Different types of distance education like print based, televisual based, audio based, 
multi-media based, web-based, mobile technology-based distance education should be practices instead of only computer and internet-based distance education. On top, both the participants and trainers involved in the distance education program should be well organized and focused about the training goal to get the desired result. (See Figure 1)

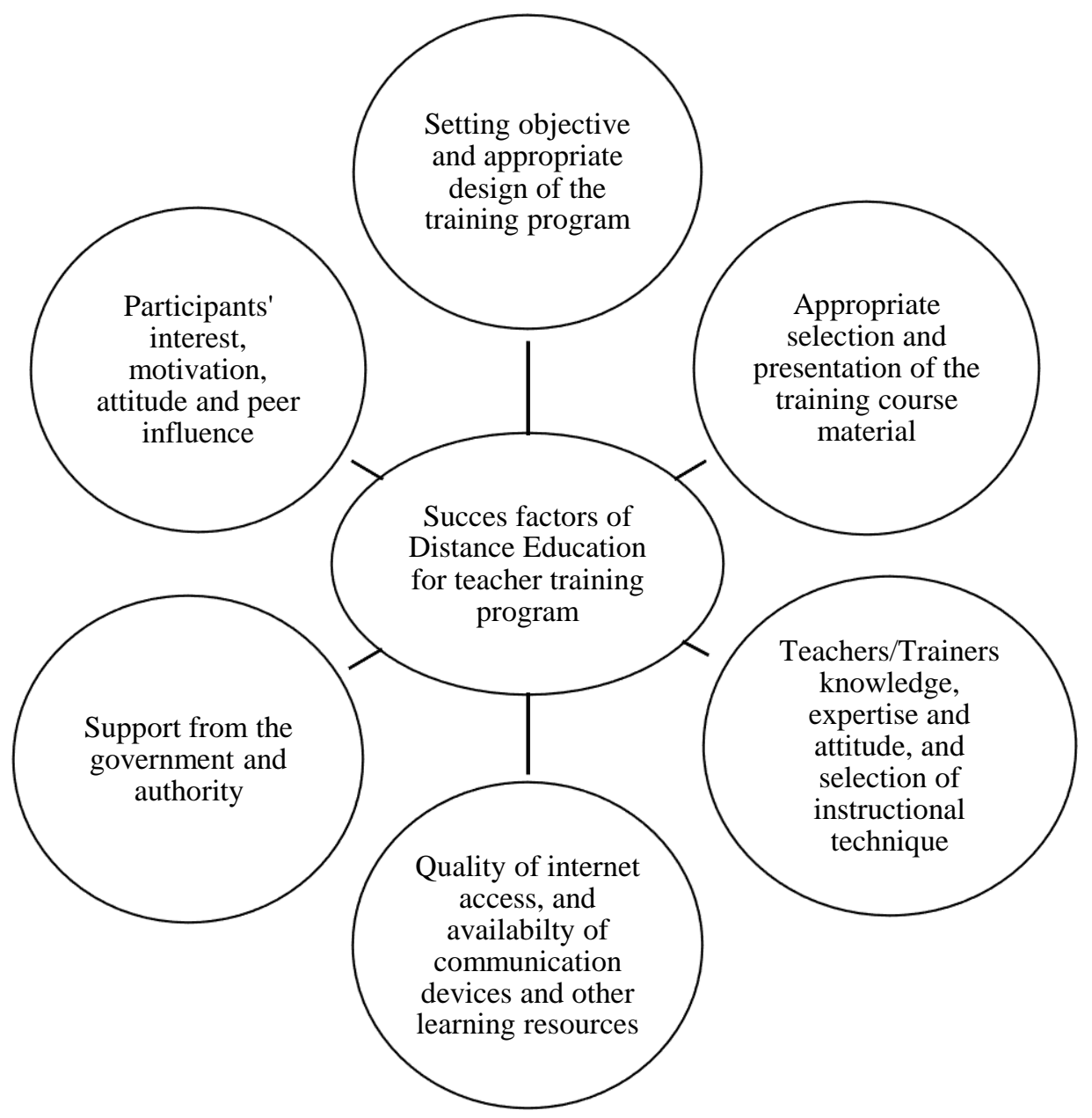

Figure 1: Framework of distance education for teacher training program

\section{Discussion}

It is evidently proven that, like other countries, in Bangladesh qualified and well-trained teachers are required to provide quality education to the children. The current approach of teacher training program has been facing many challenges (i.e., inclusion of maximum number of the teachers from every part of the country, limitation of skilled trainer and training facilities, need based training for individual teacher, etc.) which need to be minimized with other possible alternatives to have an effective teacher education program. Therefore, to encounter the requirement of qualified trained teachers to provide quality education to the students, a transformation needs to be introduced in the conventional approach of teacher education to distance teacher education. Together with the present approach in teacher training program, distance teacher training program can 
provide opportunity to reach larger number of teachers, flexibility and independency to learn as per individual need.

According to Johnson \& Strange (2007) [cited in Hannum et. al., 2009] rural schools face unique challenges associated with geographic location, cultural diversity, and limited school and community resources. Barker and Hall (1994) have suggested distance education including the use of internet and web-based materials, interactive television, computer conferencing, and multimedia modules can be a partial solution to some of the problems' rural schools face. Many of the rural schools in Bangladesh experience difficulties to attract and retain qualified and experienced teachers. Therefore, shortage of quality teachers is a common problem in most of the schools. On top, if the existing teachers are not well trained, the quality of teaching will surely deteriorate and learners will be the most deprived stakeholder.

Distance education has been used for different audiences and purposes within teacher education and like other conventional methodologies, it has strengths and weaknesses and to have success the methods of distance education program need to be in conjunction with other methods (Perraton \& Potashnik, 1997). According to them, the effectiveness of distance education can be measured in at least five ways: looking at its success in reaching audiences, in completion rates of those following distance-education courses, in their examination results, in their learning gains, and in the effects on teachers' classroom practice.

Distance education has a vital role in continuous development for teachers by offering in-service training. It can be used as an effective approach to educate a large number of teachers about the recent knowledge and skills without physical presence in training centers and help them to adapt with new changes during this pandemic situation.

Finally, this study found overwhelming positive support for distance education in teacher training program by the teachers from rural areas. The majority of rural school teachers felt the necessity of distance education as an alternative for their professional development in this crisis pandemic moment and they want this approach to be continued even the pandemic comes to an end as the distance education will give them more flexibility, accessibility and need based training support whenever they require. The experts also felt that the distance education programs can be used in teacher training program to meet the needs of the teachers in the changing time and with the introduction of distance education more teacher from remote areas, especially female teachers will get the opportunity to participate in the teacher development program. Both the teachers and experts agreed that with the advancement of modern technology and communication facility, time has come to rethink and redesign the traditional face-to-face training approach with alternatives like distance education in the midst of coronavirus pandemic situation. 


\section{Conclusion}

The teacher training programs of Bangladesh are principally operated by following a face-to-face, classroom-oriented approach. However, the outbreak of the COVID-19 pandemic and the closure of educational institutions have forced the government, administrators and educators to focus on online-based distance education in educational institutions.

Spreading the concept of distance education and its implementation in teacher training program will help the education administrator, teacher trainers and policy makers to take necessary decision to improve quality of teaching and teachers during and after the pandemic period. In Bangladesh, a project named 'Teaching Quality Improvement (TQI)' has been run to improve the quality of teaching and teachers. Nonetheless, it is very hard for the government and the authority to include a huge number of teachers in the quality improvement training program due to lack of proper resource, skilled training personnel, logistic supports and time limitations. Thus, if distance learning is been introduce to the teacher training program, it will be more effective, time saving and most importantly it will cover most teachers from the rural area.

This study is limited to the sample and the respondents who provided data. The results may be generalizable for the teachers in rural schools having the similar criteria. Data for this study were collected at one particular point of time. Thus, the results may differ in following years.

\section{Conflict of Interest Statement}

The author declares no conflicts of interests.

\section{About the Author}

Md. Solaiman Jony currently works as an Assistant Professor at the Institute of Education and Research, Education School, Khulna University, Bangladesh. He has research interest on 'Secondary and Tertiary level Education system', 'Relation between Assessment and Student Learning', 'Learning and Teaching Methodology', and, 'Teacher Training and Teacher Education'.

\section{References}

Asian Development Bank Validation Report. (2015, November). Bangladesh: Teaching Quality Improvement in Secondary Education Project. Reference Number: PVR-432, Project Number: 26061, Loan Number: 2101. https://www.adb.org/sites/default/files/evaluation-document/177269/files/pvr432.pdf 
Al-Nuaimy, E. A., Twaij, A. H. A. \& Mahmood, H. A. (2021). Importance of Distance Education and its Rise during the Period COVID-19. International Journal of Educational Researchers, 12(2), 29-34.

Barker, B. O., \& Hall, R. F. (1994). Distance education in rural schools: Technologies and practice, Journal of Research in Rural Education, 10(2), 126-128.

Burns, M. (2011). Distance education for teacher training: Modes, models, and methods. Education Development Center, Inc.

Carr, R., Fung, Y., \& Chan, S. K. (2002). Distance education for teacher education: Hong Kong experience. Journal of In-service Education, 28(1), 163-178.

Cresswell, J. W. (2012). Educational Research: Planning, Conducting, and Evaluating Quantitative and Qualitative Research (4th ed.). Pearson Education Inc.

Gopal, R., Singh, V., \& Aggarwal, A. (2021). Impact of online classes on the satisfaction and performance of students during the pandemic period of COVID 19. Education and Information Technologies, 1-25.

Gultekin, M. (2006). Using of Distance Education Approach in Teacher Training: Anadolu University Open Education Model. Turkish Online Journal of Educational Technology-TOJET, 5(1), 101-116.

Hannum, W. H., Irvin, M. J., Banks, J. B., \& Farmer, T. W. (2009). Distance education use in rural schools. Journal of Research in Rural Education (Online), 24(3), 1-15.

Hattangdi, A., Jha, S., \& Ghosh, A. (2010). A literature review of the perceptions of faculty about technology enabled distance education. International Journal of Arts and Sciences, 3(18), 379-390.

Jonassen, D. H., Carr, Chad., Yuch, Hsiu-Ping (1998). Computers as Mindtools for Engaging Learners in Critical Thinking. TechTrends, 43(2), 24-32.

Jonassen, D. H. (2000). Computers as Mindtools for Schools: Engaging Critical Thinking. Prentice Hall.

Khan, M. M., Rahman, S. T., \& Islam, S. T. A. (2021). Online Education System in Bangladesh during COVID-19 Pandemic. Creative Education, 12(2), 441-452. https://doi.org/10.4236/ce.2021.122031

Ministry of Education, Government of the People's Republic of Bangladesh. (2016). National Education Policy 2010. Retrieve from https://moedu.gov.bd/site/page/318a22d2-b400-48a7-8222-303ab11cc205/-

Perraton, H., \& Potashnik, M. (1997). Teacher education at a distance. Education and Technology Technical Notes Series, 2(2), 1-39.

Rahman, F., Jumani, N. B., Akhter, Y., Chisthi, S. U. H., \& Ajmal, M. (2011). Relationship between training of teachers and effectiveness teaching. International Journal of Business and Social Science, 2(4), 150-160.

Rockoff, J. E. (2004). The impact of individual teachers on student achievement: Evidence from panel data. American Economic Review, 94(2), 247-252.

Sarkar, S. S., Das, P., Rahman, M. M., \& Zobaer, M. S. (2021). Perceptions of Public University Students towards Online Classes during COVID-19 Pandemic in Bangladesh. Frontiers in Education, 6. https://doi.org/10.3389/feduc.2021.703723 
Sifuna, D. N. (2011). The role of distance teacher education in increasing the supply of primary school teachers in Sub-Saharan Africa. Journal of International Cooperation in Education, 14(2), 205-220.

Shah, Muhammad. (n.d.). Teacher Training Through Distance Education (Concept, Effectiveness and Some Obstacles). Retrieve from https://www.cemca.org/ckfinder/userfiles/Shah Muhammad 0244.pdf

Shahriar, S. H. B., Arafat, S., Sultana, N., Akter, S., Khan, M. M. R., Nur, J. E. H., \& Khan, S. I. (2021). The transformation of education during the corona pandemic: exploring the perspective of the private university students in Bangladesh. Asian Association of Open Universities Journal. https://doi.org/10.1108/AAOUJ-02-2021$\underline{0025}$

Tabassum, M., Mannan, S. E., Parvej, M. I., \& Ahmed, F. (2021). Online Education during COVID-19 in Bangladesh: University Teachers' Perspective. Aquademia, 5(1), ep21005. https://doi.org/10.21601/aquademia/9611

Tavukcu, T., Arapa, I., \& Özcan, D. (2011). General overview on distance education concept. Procedia-Social and Behavioral Sciences, 15, 3999-4004.

World Bank. (2021, April 18). Keeping Bangladesh's Students Learning During the COVID-19 Pandemic.

Retrieves from https://www.worldbank.org/en/results/2021/04/18/keeping-bangladesh-sstudents-learning-during-the-covid-19-pandemic 
Md. Solaiman Jony

DISTANCE EDUCATION FOR TEACHER TRAINING PROGRAM

IN RURAL AREAS: A NECESSARY STRATEGY FOR COVID-19 SITUATION

Creative Commons licensing terms

Authors will retain the copyright of their published articles agreeing that a Creative Commons Attribution 4.0 International License (CC BY 4.0) terms will be applied to their work. Under the terms of this license, no permission is required from the author(s) or publisher for members of the community to copy, distribute, transmit or adapt the article content, providing a proper, prominent and unambiguous attribution to the authors in a manner that makes clear that the materials are being reused under permission of a Creative Commons License. Views, opinions and conclusions expressed in this research article are views, opinions and conclusions of the author(s). Open Access Publishing Group and European Journal of Open Education and E-learning Studies shall not be responsible or answerable for any loss, damage or liability caused in relation to/arising out of conflict of interests, copyright violations and inappropriate or inaccurate use of any kind content related or integrated on the research work. All the published works are meeting the Open Access Publishing requirements and can be freely accessed, shared, modified, distributed and used in educational, commercial and non-commercial purposes under a Creative Commons Attribution 4.0 International License (CC BY 4.0). 